\title{
Predicting travel intentions using self-disclosure, trust and intimacy: the case of Tinder users during COVID-19
}

\author{
Kyrie Eleison Munoz
}

\begin{abstract}
Purpose - This paper determines how travel intentions can be predicted using self-disclosure behaviour, trust and intimacy. This case study focuses on Tinder users who utilised the application's Passport feature which allowed them to travel virtually and interact with other users around the globe amid global travel restrictions.

Design/methodology/approach - This quantitative research conveniently sampled 294 Tinder users who used the Passport feature during COVID-19 pandemic lockdowns. Data were analysed using PLS-SEM.

Findings - This study revealed that self-disclosure had a significant influence towards future travel intentions. Findings show that the more users self-disclose, the more their intent to travel increase. Trust and intimacy also had significant relationship on travel intentions while intimacy had a mediating effect between self-disclosure and travel intentions.

Practical implications - Tourism-oriented establishments and destination marketers should consider Tinder users as a market segment of future tourists. These users have developed travel intentions through in-app interactions and thus comprise an untapped market of potential tourists seeking for meet-ups and niche experiences in a post-pandemic era.

Originality/value - This study provides novelty in showing the predictive relationship of self-disclosure, trust and intimacy towards travel intentions. A model consisting of these constructs in the context of online interactions was also empirically tested and found adequate to predict travel intentions.
\end{abstract}

Keywords Tinder tourism, In-app behaviours, Travel intentions, PLS-SEM, COVID-19

Paper type Research paper

\section{Introduction}

Tinder is a geosocial dating application which utilises the Internet and global positional system to scout fellow users in proximal distance to afford individuals the convenience to facilitate online encounters and offline meet-ups (Choi et al., 2016). With the temporary halt in physical mobility brought about by the COVID-19 pandemic, Tinder became a platform for maintaining connections as the application rewarded its users with a waived subscription to their Passport feature to ameliorate the negative effects of the pandemic and encourage people to stay at home (Tinder, 2020). The Passport feature allows users to change their locations and interact with other users from anywhere across the globe right at the comfort of their homes. This recorded over $10 \mathrm{M}$ daily users navigating through the application with almost $6.7 \mathrm{M}$ subscribing and paying for premium features that produced a revenue of USD\$ 1.4B during the pandemic alone (Best of Apps, 2021; Tinder, 2020). Even prior to the pandemic, Tinder users have already resorted to the Passport feature to plan future travel by virtually meeting users from foreign countries in advance and establishing relationships which can help create niche interests and genuine tourism experiences from local users on their actual travel (Condie et al., 2018; Leurs and Hardy, 2019). Amid the
Kyrie Eleison Munoz is based at The International Master's Program in Tourism and Hospitality, National Kaohsiung University of Hospitality and Tourism, Kaohsiung City, Taiwan and Institute of Service Science, National Tsing Hua University, Hsinchu, Taiwan.
Received 29 September 2021 Revised 21 November 2021 23 January 2022

Accepted 25 January 2022

(c) Kyrie Eleison Munoz. Published in Journal of Tourism Futures. Published by Emerald Publishing Limited. This article is published under the Creative Commons Attribution (CC BY 4.0) licence. Anyone may reproduce, distribute, translate and create derivative works of this article (for both commercial and non-commercial purposes), subject to full attribution to the original publication and authors. The full terms of this licence may be seen at http://

creativecommons.org/licences/ by/4.0/legalcode. 
pandemic, however, it remains unclear whether travel intentions can be predicted because of the behaviours and interactions users have facilitated inside the application.

Inside Tinder, users present themselves using profiles to earn matches from likeminded users to facilitate interactions and relationships (Kallis, 2020). Users mimic social cues such as small talks, intimacies and at times courtships with the end goal of building communities, friendships or romantic relationships (Petrychyn et al., 2020). These relationships flourish because of a systematic process of revealing oneself through self-disclosure behaviour. Self-disclosure pertains to how people reveal specific details about themselves to establish and sustain relationships with others (Altman and Taylor, 1973; Derlega et al., 1993). Tinder users construct lasting impressions through continuous self-disclosure which leads to relationships (Ward, 2016). Despite emergent findings in Tinder Tourism literature suggesting that some users had no intention of meeting their online counterparts (James et al. , 2019), Tinder is still considered as a temporary space where users interact before they gain motivation to conduct physical encounters with other users (Kallis, 2020; Miller, 2019; Timmermans and De Caluwé, 2017; Ward, 2017) or travel to the other user's destination (Leurs and Hardy, 2019). In this vein, this paper aims to investigate how users who remain at home amid global lockdowns develop travel intentions because of in-app interactions.

Before meeting or travelling in the physical realm, however, the reciprocation of trustworthy and intimate behaviours surrounds the concept of self-disclosure and should be given due consideration (Carpenter and Greene, 2015; Lieberman and Schroeder, 2020). Subsequently, the Tinder Passport feature affects the relationship-building process among users as the formation of trust and intimacy are accelerated during in-app interactions (James et al., 2019). This implies that appropriate examination of how disclosing personal circumstances through interactions, especially during the COVID-19 pandemic, can lead to intimate relations as well as subsequent behavioural intentions on Tinder. Prompted with these phenomena, there is a need to provide theoretical evidence on the relationship among self-disclosure, trust and intimacy towards future travel intentions. This study aims to create a baseline model using Tinder users as a case study to determine whether such constructs can predict future travel intentions.

\section{Literature review and hypothesis development}

\section{Self-disclosure}

Self-disclosure is defined as the "process of making the self-known to others" (Jourard and Lasakow, 1958, p. 91). In the manner of self-disclosing, individuals voluntarily and openly uncover information about themselves to other people (Krasnova et al. , 2010; Qian and Scott, 2007). Such disclosed information ranges from personal details, ideas, emotions, attitudes, beliefs and experiences (Lin and Roberts, 2020). Self-disclosure has invaluable contribution in creating and sustaining relationships (Altman and Taylor, 1973). Early studies have extensively used selfdisclosure in examining its role in relationship-building throughout the field of social sciences in the context of face-to-face interactions (Cozby, 1973; Derlega et al., 1993; Jourard, 1971); however, the recent literature explored on how people self-disclosed in online platforms, such as social media (O'Sullivan and Carr, 2018). This can perhaps be attributed to the shift from dyadic to mediated communication on today's technological era where social network usage has been getting more and more preference in interactions among people (Walsh et al. , 2020). As evidenced by various scholars (i.e. Krasnova et al., 2010; Park et al., 2011; Tang and Wang, 2012), profiles from social networking sites (SNS) have been a strong platform where disclosing personal information was made possible. Surprisingly, self-disclosing was observed to be a norm among SNS users (Koohikamali et al. , 2017) as well as in the sharing economy platforms and dating sites (Ma et al., 2017) as users frequently share content about themselves to update their online networks about what is happening to them. Similarly, Tinder is designed to enable users to selfdisclose by requiring them to upload photos of themselves in their profiles (David and Cambre,

PAGE 2 | JOURNAL OF TOURISM FUTURES $\mid$ VOL. ... NO. ... 
2016). Users are likewise encouraged to include biographies, interests and links to other SNS such as Instagram into their profiles which allows them to disclose more information about themselves to others.

\section{Trust}

The conceptualisation of trust been applied in the field of tourism to predict behavioural outcomes towards destinations (Abubakar, 2016) and brands (Lee, 2017). One of the most cited definitions of trust is attributed to the work of Mayer et al. (1995) which states that trust is "the willingness of a party to be vulnerable to the actions of another party based on the expectation that the other will perform a particular action important to the trustor, irrespective of the ability to monitor or control that other party" (p. 715). McKnight and Chervany (2001) developed a typology which distinguishes the different views on trust. The categories include disposition to trust, institutionbased trust, trusting beliefs, trusting intentions and trust-related behaviours. However, trust is a dynamic concept which has been explored to have multiple stages (Rheu et al., 2020) and thereby difficult to measure by merely describing its type. Trust, therefore, should be carefully examined on the manner how it is established. Specifically, the propensity of an individual to trust others is crucial (Mayer et al., 1995). This is because people compare and evaluate potential risks and values from the actions disclosed by individuals throughout the interpersonal interactions they have facilitated (Jones and Shah, 2016). In the context of Tinder, profiles are essential in the formation of trust as users evaluate the authenticity of the other user based on the information they have provided on their profiles (Duguay, 2017).

\section{Intimacy}

Intimacy is broadly defined as a physical, behavioural and emotional exchange of what is personal and private among individuals through both verbal and non-verbal communication (Prager, 1997; Reis and Shaver, 1988). Previous studies have regarded this concept as a gratifying and fulfilling social phenomenon (Ryff and Singer, 2000; Sperry, 2010) and have been associated with terms such as closeness, attachment and support (Prager, 1997; Sperry, 2010). Tolstedt and Stokes (1983) groups three kinds of intimacy as affective, physical and verbal. Affective intimacy deals with emotional proximity between individuals. Physical intimacy is focused on haptics and actions including sex. Lastly, verbal intimacy is about words and self-disclosure. Early scholars have concluded that intimacy is promoted by self-disclosure (Greene et al., 2006; Laurenceau et al., 2004). With the current digital age, social intimacies have been observed to have permeated in online platforms which served as a space to facilitate online intimacies that are comparable with the conventional relationships facilitated offline (Lomanowska and Guitton, 2016). In fact, a growing number of individuals prefer creating relationships online (Nayar and Koul, 2020). This is particularly true for Tinder which was observed to facilitate "screened intimacies" where users have engaged in quick closeness and intimate relations through in-app interactions (David and Cambre, 2016).

\section{Hypothesis development}

Developing trust among strangers is a key challenge because of the probability that users would take advantage of others given the anonymity and mediated nature of technological communication (Horton and Zeckhauser, 2016). To bridge this dilemma, several scholars found that self-disclosure plays a role in facilitating trust across online platforms. On Facebook, Nemec Zlatolas et al. (2019) determined that trust and self-disclosure had a negative association when social identity of the user is not noticeable. Similarly, a study on Airbnb by Broeder and Crijns (2019) uncovered that self-disclosure influenced trust. It appears that profiles that have salient pictures (i.e. clear depiction of the eyes) are perceived to have higher self-disclosure which influences trust of the other user. In another Airbnb study, it was revealed that hosts who disclose longer information and substantive topics in their profiles are deemed more trustworthy and hence influences users' intention to book (Ma et al., 2017). These studies indicate that users who disclose substantial amount of information about themselves to others through their profile presentations 
result to a feeling of trust. In contrast, Li et al. (2020) found out that online self-disclosure did not predict trust. Their study claims that offline interactions are the most effectual way of disclosing compared to online diaries as the former can enrich the context and conversational exchange among participants. With these current findings, this study hypothesises

H1. Self-disclosure has a significant influence of trust.

Farci et al. (2017) found out that intimacy was achieved by frequent self-disclosure behaviour in SNS. According to them, Facebook users facilitate collaborative disclosure strategies such as showing, sharing content, liking content, photo tagging and expecting mutual understanding which have developed into certain degrees of intimacies among users. Visual images and selfinformation frequently shared online were also seen to foster a level of familiarity, closeness and online intimacy among users (Houghton et al., 2018; Lin and Utz, 2017). The depth of online selfdisclosure was likewise associated in developing intimacies as friendship quality was enhanced because openly sharing personal and intimate information among users trigger feelings of closeness toward each other (Desjarlais and Joseph, 2017; Ogba et al., 2019). However, Pang (2018) found no relationship between self-disclosure and intimacy and friendship closeness in a study conducted on WeChat. In this light, this study hypothesises

H2. Self-disclosure has a significant influence on intimacy.

Self-disclosure literature narrowed down on predicting travel intention remains scant. Therefore, this research would provide novelty in establishing the relationship between these two variables. Azzahro et al. (2018) established that self-disclosure has a significant influence on the intention of users to continue using dating apps. The authors associate the users' self-disclosure behaviour with their desire to keep in touch with other users they have met inside the dating app. Similarly, Malloch and Zhang (2019) claimed that self-disclosure influenced behavioural intentions. In their experiment, selfdisclosure played a vital role in helping participants to understand information disclosed in a health poster which was useful in determining their dietary intentions. Lastly, Lee (2020) examined the influence of a journalist's self-disclosure behaviour and the audience's behavioural intentions. This study revealed that the interactions and engagements of journalists to the audience through social media had influenced intention to consume the news. Given the current phenomenon on Tinder use, this study banks on the premise of existing research in behavioural intentions by hypothesising

H3. Self-disclosure has a significant influence on travel intention.

Affective psychological responses such as trust have been investigated in recent literature to travel intention focussing on online contexts. In the study of Abubakr (2016), trust was positively related to travel intention in online community memberships. Similarly, Zhang et al. (2020) determined that interpersonal trust, relationship and offline travel decision making had significant relationships. Trust and intimacy were seen to have fostered the exchange between the online community whose attitudes, values, knowledge and experiences helped members transition from online acquaintances to offline travel companions. Trust was likewise seen as a partial mediator in destination social responsibility and intention to visit (Su et al., 2020). Thus, it is hypothesised

H4. Trust has a significant influence on travel intention.

H4a. Trust has a mediating effect on self-disclosure and travel intention.

The previous literature links trust as a vital construct in developing intimacies and relationships. In the study of Balaji et al. (2016), customers established intimacy towards services they associate trust with. This is the same with Ponder et al. (2016) who found out that customers who have higher feelings of trust toward an establishment is more willing to build intimate relations with the same. After all, intimacy is bound to develop when emotional and behavioural antecedents, such as mutuality, are built (Batra et al., 2012). Mutuality can be derived as a by-product of building trust where people compare and evaluate potential risks and values from the actions disclosed by 
individuals throughout interpersonal interactions (Jones and Shah, 2016). Therefore, it can be synthesised that the disposition of an individual to trust gives off positive impressions and intentions towards the other in the form of intimacy.

H5. Trust has a significant influence on intimacy.

Despite not having an established direct causal relationship with travel intention, similar cases of online interactions using the broader concept of behavioural intention points a relationship with intimacy. In the study conducted by Wang and Chang (2020), findings conclude that selfdisclosing enabled audiences to form a continuous viewing behaviour in the context of continued intent in patronising a Vlog. Nora (2019) also found out that high customer intimacy leads to repurchase intentions in banking products. In the same light, Rodrigues and Rodrigues (2019) argues that intimacy for neo-luxury brands serves as a mediator towards intention to purchase and word-of-mouth behaviour. Thus, it is hypothesised:

H6. Intimacy has a significant influence on travel intention.

H6a. Intimacy has a mediating effect on self-disclosure and travel intention.

Figure 1 illustrates the eight hypotheses of this study.

\section{Methodology}

This study referred to four previously published measurement scales as basis for developing the questionnaire. The self-disclosure scale (Gibbs et al., 2006), intimacy scale (Rau et al., 2008) and travel intention scale (Ryu and Jang, 2006) were adopted and followed a five-point Likert scale with response options ranging from strongly disagree to strongly agree as originally indicated in the respective studies they were adopted from. The values $1=$ strongly disagree, $2=$ disagree, $3=$ neither agree nor disagree, $4=$ agree and $5=$ strongly agree are used. The trustworthiness scale (McCroskey and Teven, 1999) was adopted using a 7-point semantic differential scale. As the original scale shows $\Pi 1, \Pi T 3$ and $\Pi T 4$ having negative semantics on the right side, this study has reverse-scored these indicators in the data cleaning phase to maintain consistency with the rest of the adopted scales.

The measurement items were adapted to suit the research context and subsequently pre-tested by three experts to ensure relevance, consistency and clarity (Hair et al., 2014). The final survey questionnaire was distributed online from April and August 2021 from a pool of Tinder users through convenience sampling. Those who have used the Tinder Passport feature for the past year was the sampling criteria. Non-probability convenience sampling was utilised as this study particularly calls for a specific set of respondents which are bound by access and time within the

\section{Figure 1 Hypothetical model}

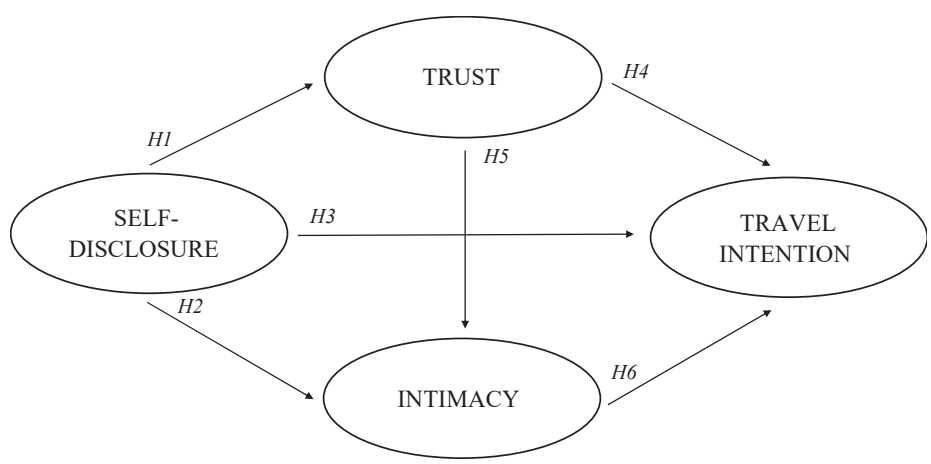


reach of the researcher (Dörnyei, 2007). Adding to this, the total population of Tinder Tourists cannot be accessed to warrant a probability randomisation to produce the sample.

An online web-based survey was chosen as a research tool since the target respondents belong to a specific niche in which the Internet can reach, compared with other offline channels (Garton et al., 1999; Wellman, 1997). Moreover, the COVID-19 pandemic has compelled the researcher to adapt to the occasion and carryout data collection in the most realistic research approaches such as online (Ali et al., 2020). A total of 294 valid responses were carried out in the data analysis which satisfies the minimum sample requirement set by power analysis to minimise the possibility of bias and errors (Hair et al., 2018; Memon et al., 2020).

Data was analysed using partial least squares-structural equation modelling (PLS-SEM) with the software SmartPLS 3.0. PLS-SEM was chosen as the suitable technique because of the exploratory and predictive nature of this research (Hair et al., 2018). The main objective of this study is to predict the determinants of travel intentions while there is scarce prior knowledge on the structural model relationships and predictive research regarding the variables on hand (Hair et al., 2019). This study would hence benefit from PLS-SEM's statistical power to examine the constructs whose theoretical and empirical support is still developing (Hair et al., 2019). Moreover, PLS-SEM is likewise suitable in this study since more than half of the measurement items do not meet acceptable kurtosis and skewness values for normal distribution (Hair et al., 2014). Utilising the bootstrapping technique in PLS-SEM can overcome this issue (Hair et al., 2014; Ramayah et al., 2018).

\section{Results}

\section{Descriptive statistics}

Table 1 summarises the respondent profile and includes sex, age, residence, education level and occupation. Data are presented using the descriptive analyses of frequency and percentage.

Male respondents accounted for $51 \%$ of the sample while female respondents represented the remaining 49\%. A great majority of the respondents is aged between 18 and 29. In terms of their residence, 19\% were from the USA while 18\% were from Singapore, 18\% from Australia, 16\% from the Philippines, $16 \%$ from the UK and $16 \%$ from other locations. Most were students (44\%) and $33 \%$ employed full-time and 23\% neither employed nor a student.

\section{Evaluation of reflective model}

The model estimation conducted in this study shows satisfactory internal consistency with composite reliability of self-disclosure (0.94), trust (0.91), intimacy (0.89) and travel intentions

\section{Table 1 Demographic summary of respondents $(N=294)$}

\begin{tabular}{llcc} 
Profile of respondents & $\mathrm{n}$ & $\%$ \\
\hline Sex & Male & 151 & 51 \\
Age & Female & 143 & 49 \\
& $18-29$ & 178 & 61 \\
\multirow{3}{*}{ Residence } & $30-49$ & 79 & 27 \\
& $>50$ & 37 & 13 \\
& USA & 57 & 19 \\
& Singapore & 54 & 18 \\
& Australia & 48 & 16 \\
& The Philippines & 46 & 16 \\
Occupation & UK & 41 & 14 \\
& Others & 48 & 16 \\
& Student & 129 & 44 \\
& Employed (full-time) & 97 & 33 \\
& Unemployed & 68 & 23
\end{tabular}

PAGE 6 | JOURNAL OF TOURISM FUTURES | VOL 
(0.82). These high values exhibit desirable reliability of the indicators (Nunnally, 1978) and adequate internal consistency (Hair et al., 2019; Gefen et al., 2000). Table 2 reports the outer loading of the indicator items of reflective measurement models. According to Hair et al. (2014), the outer loadings must indicate a value $\geq 0.708$ to determine reliability whereas indicators whose outer loadings fell below the threshold should be subjected to a purification process. Indicators that do not contribute to the average variance extracted (AVE) of the construct should be deleted (Hair et al., 2014). Results show that items of IN had lower outer loadings indicating that such items do not converge nor captured by the constructs they reflect (Hair et al., 2014). Such indicators perhaps do not measure IN of Tinder users. After all, intimacy encompasses verbal and affective

\section{Table 2 Indicator outer loadings}

Self-disclosure

SD 1 - I am always honest in my self-disclosures to my Tinder match loadings

SD 2 - My statements about my feelings, emotions and experiences to my Tinder match are

SD 3 - The things I reveal about myself to my Tinder match are always accurate reflections of who I really am

SD 4 - I often discuss my feelings about myself with my Tinder match

SD 5 - I usually communicate about myself for fairly long periods at a time with my Tinder match

SD 6 - I do not often communicate about myself with my Tinder match

SD 7 - I don't express my personal beliefs and opinions to my Tinder match

SD 8 - I often disclose negative things about myself to my Tinder match

SD 9 - I usually disclose only positive things about myself to my Tinder match

SD 10 - When I express my personal feelings with my Tinder match, I am always aware of what I am doing and saying

SD 11 - When I reveal my feelings about myself with my Tinder match, I consciously intend to do so

Trust

Tा 1 - After some time, I feel my Tinder match is .... Honest- Dishonest

Tा 2 - After some time, I feel my Tinder match is .... Untrustworthy- Trustworthy

Tा 3 - After some time, I feel my Tinder match is .... Honorable- Dishonorable

Tा 4 -After some time, I feel my Tinder match is .... Moral- Immoral

Tा 5 - After some time, I feel my Tinder match is .... Unethical- Ethical

Tा 6 - After some time, I feel my Tinder match is .... Phony - Genuine

Intimacy

IN 1 - Communication between me and my Tinder match is limited to just a few specific topics

IN 2 - Communication between me and my Tinder match ranges over a wide variety of topics

IN 3 - Once we get started, me and my Tinder match move easily from one topic to another IN 4 - Me and my Tinder match contact each other in a variety of ways besides Tinder

IN 5 - I usually tell my Tinder match exactly how I feel

IN 6 - I try to keep my personal judgements to myself when my Tinder match says or does something with which I disagree

IN 7 - I have told my Tinder match what I like about him or her

IN 8 - I feel I could confide with my Tinder match about almost anything

IN 9-Communication between me and my Tinder match stays on the surface of most topics IN 10 - I have told my Tinder match things about myself that he or she could not get from any other source

IN 11 - I would never tell my Tinder match anything intimate or personal about myself

Travel intention

TI 1 - I will visit my Tinder match's country in the future 
cues and the context of this study can only measure its verbal aspect (Rau et al., 2008). Hence, subsequent purification of such indicators was performed using the PLS algorithm. In summary, initial indicators of self-disclosure, trustworthiness and travel intention were maintained while only 3 out of 11 indicators of intimacy was carried out in the succeeding analyses.

Table 3 reports the AVE, outer loadings, $t$-values, $p$-values and significance levels of the indicators in the purified reflective model. Findings reveal that indicator reliability is confirmed with outer loadings exceeding the 0.708 threshold value recommended by Hair et al. (2019). Therefore, reflective items were all significant $(p<0.001)$. The AVE of self-disclosure, trust, intimacy and travel intention were likewise adequate and ranges from 0.54 to 0.76 (Hair et al., 2019). By having acceptable AVE values for all constructs confirms adequate convergent validity is met based on the minimum requirements (Fornell and Larcker, 1981).

Fornell-Larcker criterion and HTMT ratio were used to provide a holistic comparison for discriminant validity (Hair et al., 2019). Table 4 confirms discriminant validity by means of the Fornell-Larcker criterion as the AVE of each is higher than the latent variable's highest squared correlation and (Chin, 1998, 2010; Fornell and Larcker, 1981).

Table 3 Convergent validity and indicator reliability of purified reflective model

\begin{tabular}{|c|c|c|c|c|c|}
\hline Reflective indicator $\leftarrow L V$ & AVE & Outer loadings & t-values & p-values & Significance \\
\hline Self-disclosure & 0.65 & & & & \\
\hline $\mathrm{SD} 1 \leftarrow \mathrm{SD}$ & & 0.80 & 29.13 & 0.000 & $\star \star \star ~$ \\
\hline $\mathrm{SD} 2 \leftarrow \mathrm{SD}$ & & 0.63 & 39.67 & 0.000 & 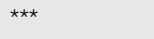 \\
\hline $\mathrm{SD} 3 \leftarrow \mathrm{SD}$ & & 0.81 & 25.28 & 0.000 & $\star \star \star ~$ \\
\hline $\mathrm{SD} 5 \leftarrow \mathrm{SD}$ & & 0.78 & 22.13 & 0.000 & $\star \star \star$ \\
\hline $\mathrm{SD} 6 \leftarrow \mathrm{SD}$ & & 0.75 & 32.45 & 0.000 & $\star \star \star ~$ \\
\hline $\mathrm{SD} 7 \leftarrow \mathrm{SD}$ & & 0.83 & 33.08 & 0.000 & $\star \star \star \star ~$ \\
\hline $\mathrm{SD} 8 \leftarrow \mathrm{SD}$ & & 0.84 & 50.47 & 0.000 & 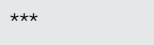 \\
\hline $\mathrm{SD} 9 \leftarrow \mathrm{SD}$ & & 0.85 & 38.46 & 0.000 & 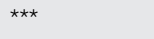 \\
\hline SD $10 \leftarrow S D$ & & 0.79 & 40.47 & 0.000 & $\star \star \star ~$ \\
\hline $\mathrm{SD} 11 \leftarrow \mathrm{SD}$ & & 0.81 & 40.71 & 0.000 & $\star \star \star$ \\
\hline Trust & 0.69 & & & & \\
\hline$\Pi 1 \leftarrow \Pi$ & & 0.88 & 64.2 & 0.000 & 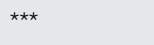 \\
\hline$\Pi 2 \leftarrow \pi$ & & 0.74 & 26.8 & 0.000 & $\star \star \star$ \\
\hline$\pi 3 \leftarrow \pi$ & & 0.89 & 67.6 & 0.000 & $\star \star \star$ \\
\hline$\Pi 4 \leftarrow \pi$ & & 0.86 & 48.1 & 0.000 & 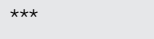 \\
\hline$\Pi 5 \leftarrow \Pi$ & & 0.76 & 20.3 & 0.000 & 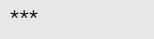 \\
\hline$\pi 6 \leftarrow \pi$ & & 0.85 & 51.5 & 0.000 & 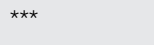 \\
\hline Intimacy & 0.82 & & & & \\
\hline $\mathbb{I N} 1 \leftarrow \mathbb{I N}$ & & 0.88 & 58.7 & 0.000 & $\star \star \star$ \\
\hline IN $2 \leftarrow S D$ & & 0.93 & 130.6 & 0.000 & $\star \star \star *$ \\
\hline $\mathrm{IN} 9 \leftarrow \mathrm{SD}$ & & 0.91 & 73.9 & 0.000 & 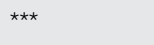 \\
\hline Travel intention & 0.74 & & & & \\
\hline $\mathrm{TI} 1 \leftarrow \mathrm{Tl}$ & & 0.90 & 60.0 & 0.000 & $\star \star \star$ \\
\hline $\mathrm{TI} 2 \leftarrow \mathrm{TI}$ & & 0.82 & 36.0 & 0.000 & 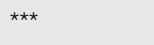 \\
\hline $\mathrm{TI} 3 \leftarrow \mathrm{TI}$ & & 0.85 & 52.7 & 0.000 & 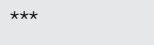 \\
\hline
\end{tabular}

Table 4 Discriminant validity using Fornell-Larcker criterion

\begin{tabular}{lllll} 
& IN & $S D$ & $T$ TI \\
\hline IN & 0.91 & & & \\
SD & 0.25 & 0.80 & 0.867 & \\
TI & 0.24 & 0.65 & 0.07 & 0.85
\end{tabular}


Given that constructs were not similar, this study accepts HTMT values below 0.85 . The constructs did not exceed the HTMT ratio of 0.85 which further affirms discriminant validity (Hair et al., 2019).

\section{Evaluation of structural model}

VIF values of all indicators are less than the significant collinearity threshold of 5 which suggests that there are no potential collinearity issues and bias in structural model estimations computations (Hair et al., 2019). Therefore, all latent constructs were retained and the study proceeds to the evaluation of the structural model. A bootstrapping procedure was then conducted using 294 cases and 5,000 subsamples to determine the significance of hypothesised relationships among the constructs (Hair et al., 2019).

The results shown on Table 5 support the hypotheses. $\mathrm{H} 1$ is accepted with a significant positive effect of self-disclosure on trust $(\beta=0.14, p<0.05)$. This is the same with $\mathrm{H} 2$ with a significant positive effect of self-disclosure on intimacy $(\beta=0.13, p<0.001)$. H5 is likewise accepted with trust having a highly significant positive effect on intimacy ( $\beta=0.83, p<0.001)$. Significantly, the three hypotheses proposing the relationship with travel intention were supported. Selfdisclosure shows a significant effect on travel intention $(\beta=0.60, p<0.001)$ while trust has negative influence on travel intention $(\beta=-0.34, p<0.001)$. Lastly, intimacy has significant influence on travel intention $(\beta=0.38, p<0.001)$. The effects of the two mediators, trust and intimacy, were likewise tested. Results of the mediation analysis shows that intimacy $(\gamma=0.05$, $p<0.001)$ partially mediates self-disclosure and travel intention while trust $(\gamma=-0.48$, $p=0.064$ ) did not have a mediating effect (Nitzl et al., 2016). The path coefficient results are summarised in Figure 2.

The coefficient of determination $\left(R^{2}\right)$ values of the endogenous latent variables can be interpreted for intimacy (0.74) as substantial, travel intention (0.46) approaching moderate and trust (0.02) as weak (Hair et al., 2019). The present case shows that the model on hand's in-sample explanatory power in predicting for travel intention was adequate. Results likewise show small to large effect sizes $\left(f^{2}\right)$ (Cohen, 1988). Large effects were observed between SD $\rightarrow \mathrm{TI}(0.62)$ and $\mathrm{TT} \rightarrow \mathrm{IN}(0.64)$ while small effects exist for SD $\rightarrow \mathrm{IN}(0.07), \mathrm{SD} \rightarrow \mathrm{T}(0.02), \Pi \rightarrow \mathrm{TI}(0.06), \mathrm{IN} \rightarrow \mathrm{Tl}(0.07)$.

\section{Discussions}

Findings of this study affirm the significant relationship between these variables. $\mathrm{H} 1 \mathrm{complements}$ previous studies which found out that self-disclosure has influenced trust (Broeder and Crijns, 2019; Nemec Zlatolas et al., 2019). Unlike Li et al. (2020), this study established that online selfdisclosure plays a crucial role in relationship building. The high effect on this variable suggests that respondents give great consideration on the importance of self-disclosed information by other Tinder users. This can be associated with the fact that Tinder users being exposed with other users' photos, descriptions and interest tags. This finding is especially important as cybercrimes

Table 5 Bootstrapping results for the structural model

\begin{tabular}{|c|c|c|c|c|c|c|}
\hline & Original sample & t-values & p-values & Sig. level & Hypotheses & Remark \\
\hline $\mathrm{SD} \rightarrow \pi$ & 0.14 & 2.33 & 0.020 & $\star \star$ & $\mathrm{H} 1$ & Supported \\
\hline $\mathrm{SD} \rightarrow \mathbb{I N}$ & 0.13 & 4.04 & 0.000 & 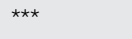 & $\mathrm{H} 2$ & Supported \\
\hline $\mathrm{SD} \rightarrow \mathrm{Tl}$ & 0.60 & 13.59 & 0.000 & *** & H3 & Supported \\
\hline $\mathrm{TT} \rightarrow \mathrm{TI}$ & -0.34 & 3.68 & 0.000 & 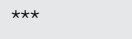 & $\mathrm{H} 4$ & Supported \\
\hline $\mathrm{SD} \rightarrow \mathrm{T} \rightarrow \mathrm{Tl}$ & -0.05 & 1.85 & 0.064 & NS & $\mathrm{H} 4 \mathrm{a}$ & Not supported \\
\hline$\Pi \rightarrow \mathbb{I N}$ & 0.83 & 57.62 & 0.000 & 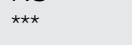 & $\mathrm{H} 5$ & Supported \\
\hline $\mathrm{IN} \rightarrow \mathrm{TI}$ & 0.38 & 3.99 & 0.000 & $\star \star \star \star ~$ & $\mathrm{H} 6$ & Supported \\
\hline $\mathrm{SD} \rightarrow \mathrm{IN} \rightarrow \mathrm{TI}$ & 0.05 & 3.21 & 0.00 & 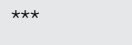 & $\mathrm{H} 6 \mathrm{a}$ & Supported \\
\hline
\end{tabular}

VOL. $\mathbf{m}$ NO. $\mathbf{m} \mid$ JOURNAL OF TOURISM FUTURES $\mid$ PAGE 9 


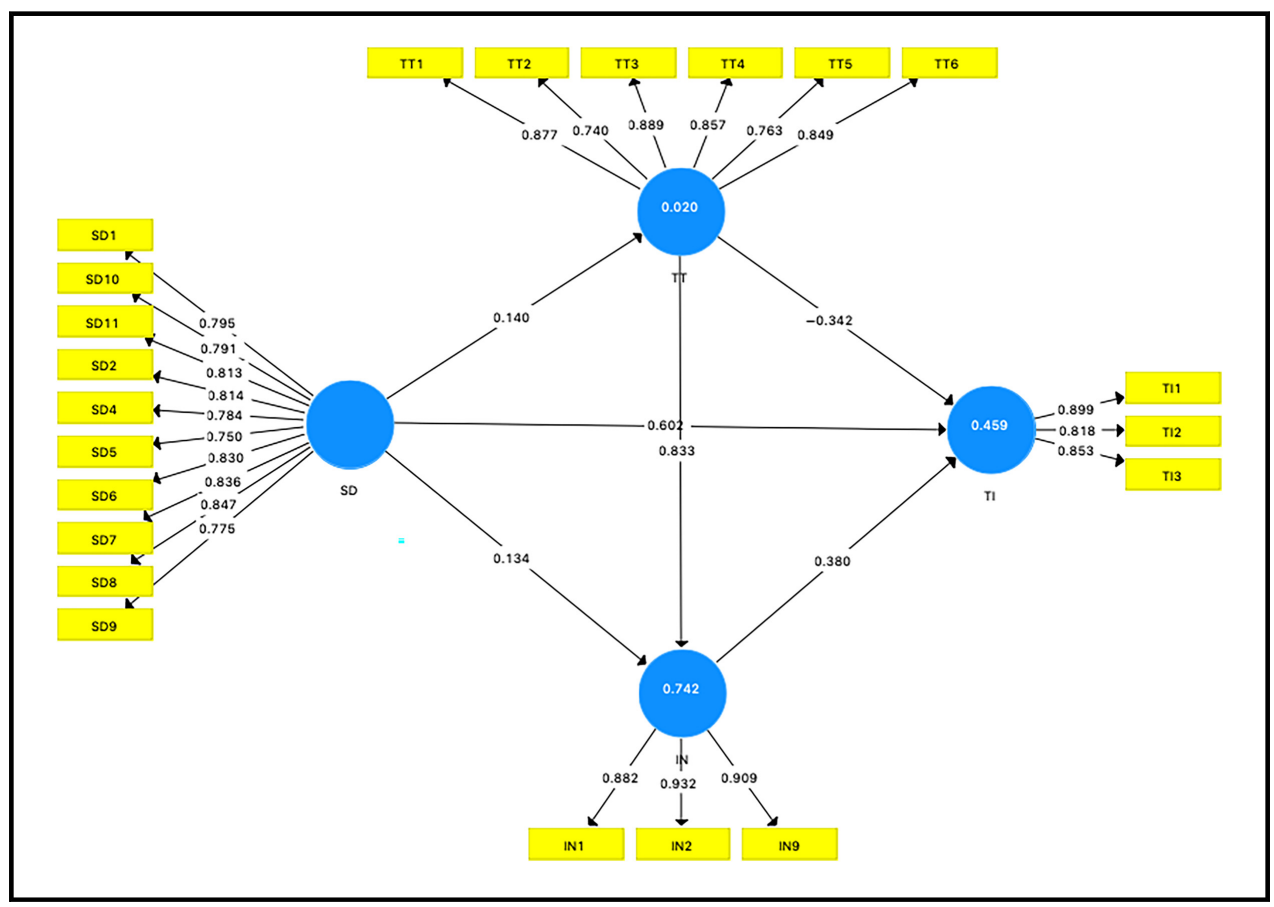

rose to an alarming scale during the pandemic period when it was observed that online users began impersonating and spread disinformation to fellow users to commit fraud (Naidoo, 2020). Moreover, users eventually exchange messages which compel them to disclose and elaborate more information about themselves - a clear indicator how self-disclosure influences trust through acts of reciprocity and vulnerability. This study likewise confirms the influence of self-disclosure on intimacy similar to the findings of the previous literature (Desjarlais and Joseph, 2017; Lin and Utz, 2017; Ogba et al., 2019). Findings also reveal that the manner of user-to-user self-disclosure fosters close interactions. For example, the frequent verbal interaction and communication exchange among users proved to be essential in relationship building. This can perhaps be traced to the whole purpose of Tinder as a dating application which aims to connect likeminded individuals who would share common interests in their conversations. Likewise, users are perhaps actively and consciously looking for online relationships (Lomanowska and Guitton, 2016). This leads to the notion that users, at this point, are willingly and deliberately disclosing information about the self in their message which leads to meaningful banters and eventually warm intimate feelings.

Another interesting finding was in $\mathrm{H} 3$ which provides novel empirical support for the relationship between self-disclosure and travel intention. This is analogous to the conclusion of previous research exploring the relationship of self-disclosure and behavioural intention (Azzahro et al., 2018; Wang and Chang, 2020). Findings of this study suggest that larger amounts of information being disclosed by a user increase the intention of the other user to travel. This implies that Tinder users develop a strong motivation to travelling to the other's geographic location after sufficient inapp interactions and self-disclosure behaviour. The findings on $\mathrm{H} 4$ also align with previous literature confirming the significant relationship between trust and travel intention (Abubakar, 2016; Zhang et al., 2020). However, findings show that a negative influence among the two constructs. This means that Tinder users have higher travel intentions when trust is low. According to Davari and Jang (2021), potential tourists with low levels of trust can yield high levels of travel intention as they associate future travel with past experiences and relationships with their hosts. In this study, it can be inferred that users who have low trust towards their current online Tinder match would still have strong intention to travel as they remain optimistic perhaps from previous meet-ups and 
experiences. This further complements the finding on $\mathrm{H} 4 \mathrm{a}$ which does not show the mediating effect of trust on the relationship between self-disclosure and travel intention.

Findings on $\mathrm{H} 5$ reveal that the closeness among Tinder users and their matches is associated with trust. These findings follow the theoretical implications of studies which investigated on the relationship of trust and intimacy in marketing literature which argued that customers tend to develop intimacy towards those that have gained their trust (Balaji et al., 2016; Ponder et al., 2016). After all, users who trust each other are likely to build intimate relations. Lastly, findings affirm previous research on intimacy and behavioural intention (Nora, 2019; Wang and Chang, 2020) with $\mathrm{H} 6$ and further indicating a mediating effect of intimacy between self-disclosure and travel intention as hypothesised in $\mathrm{H6a}$. The intention to travel to meet their matches is often stirred by the curiosity to know the other in person and a travel intention can be developed with the intimate insider information the other person provides about their country of origin. Likewise, providing constant self-disclosed information coupled with close and intimate affinity between users could ultimately kick an intention to meet the other or travel to the destination which a user have been enticed to go. During the in-app interactions, "inside" information shared by locals and potential hosts might have influenced potential guests to be enthusiastic and excited thus stimulating a strong intent to travel (James et al., 2019; Leurs and Hardy, 2019).

\section{Conclusion and implications}

This study draws its theoretical contribution on a proposed model which was the first to empirically test the predictive relationship between self-disclosure and travel intentions which has not been explored in previous literature. Using the case of Tinder users during the COVID-19 pandemic, the adequacy of the predictive relevance of the said model was determined with self-disclosure having a large effect size on travel intention. In this regard, this study advances the understanding of selfdisclosure which can be used in predicting future travel intentions in a post-pandemic world. Moreover, findings of this study provide empirical support in predicting travel intentions with trust and intimacy. This study also provides managerial contributions by determining how the future of tourism can benefit from Tinder users. Leisure, entertainment and hospitality establishments can serve as the venues where users can meet-up in the future since public places can reduce risky encounters which Tinder Tourists often consider a threat to their security (Leurs and Hardy, 2019). Alternatively, travel agencies and destination managers ought to consider developing travel packages specifically targeted to Tinder users who prefer to enjoy niche experiences featuring the destination's tourist spots, culture and new experiences rather than meet-ups. Destination marketing organizations can also reinforce the information users' online counterparts have been providing them by strategically using Tinder as a platform for marketing and promotions. All in the same, findings of this study accentuate a futuristic perspective on post-COVID-19 tourism industry by introducing the untapped niche of Tinder users whose future travel intentions and transition from online to offline travel can be predicted using self-disclosure, trust and intimacy.

In spite of the contributions presented, this study is not without limitations. First, the samples obtained were drawn conveniently and could not generalise the entire population of Tinder users. Succeeding studies could bridge this gap by expanding the sampling method. Second, gender warrants a further interrogation in Tinder Tourism literature. Although this study did not reveal emergent findings on gender differences among users, previous studies have found out that this can be a factor affecting travel experiences (see Leurs and Hardy, 2019; James et al., 2019). In this light, constructs affecting these travel experiences such as risk, safety and security should also be investigated (see Gajic et al., 2021; Matiza, 2020). Moreover, the influence and impact of COVID-19 on travel intentions should be incorporated in future research as health issues affect tourist behaviour and perception during global pandemics. Lastly, the model presented should only be treated as a baseline and should be subsequently applied, expanded and confirmed by future studies within and outside the context of Tinder. This allows succeeding research to expand the knowledge and understanding on predicting travel intentions using self-disclosure. 


\section{References}

Abubakar, A.M. (2016), "Does eWOM influence destination trust and travel intention: a medical tourism perspective", Economic Research-Ekonomska istraživanja, Vol. 29 No. 1, pp. 598-611.

Ali, S.H., Foreman, J., Capasso, A., Jones, A.M., Tozan, Y. and DiClemente, R.J. (2020), "Social media as a recruitment platform for a nationwide online survey of COVID-19 knowledge, beliefs, and practices in the United States: methodology and feasibility analysis", BMC Medical Research Methodology, Vol. 20, pp. 1-11, doi: 10.1186/s12874-020-01011-0.

Altman, I. and Taylor, D. (1973), Social Penetration: The Development of Interpersonal Relationships, Holt, New York, NY.

Azzahro, F., Hidayanto, A.N., Maulida, R.M., Zhu, Y.Q. and Sandhyaduhita, P.I. (2018), "Exploring the influential factors in continuance usage of online dating apps: gratification, subjective well-being and selfdisclosure", PACIS, p. 322

Balaji, M.S., Roy, S.K. and Wei, K.K. (2016), "Does relationship communication matter in B2C service relationships?", Journal of Services Marketing, Vol. 30 No. 2, pp. 186-200, doi: 10.1108/JSM-08-2014-0290.

Batra, R., Ahuvia, A. and Bagozzi, R.P. (2012), "Brand love", Journal of Marketing, Vol. 76 No. 2, pp. 1-16, doi: 10.1509/jm.09.0339.

Best of Apps (2021), "Tinder revenue statistics", Best of Apps, 12 July, available at: https://www. businessofapps.com/data/tinder-statistics/.

Broeder, P. and Crijns, K. (2019), "Self-disclosure and trust on Airbnb: a cross-cultural perspective", in ZimandSheiner, D. and Strovsky, D. (Eds), Storytelling across Platforms: Managing Corporate and Marketing Communications from a Storytelling Perspective, Ariel University, pp. 160-171.

Carpenter, A. and Greene, K. (2015), "Social penetration theory", The International Encyclopedia of Interpersonal Communication, pp. 1-4, doi: 10.1002/9781118540190.wbeic160.

Chin, W.W. (1998), "The partial least squares approach to structural equation modeling", Modern Methods for Business Research, Vol. 29 No. 2, pp. 295-336.

Chin, W. (2010), "How to write up and report PLS analyses", in Esposito Vinzi, V., Chin, W.W., Henseler, J. and Wang, H. (Eds), Handbook of Partial Least Squares: Concepts, Methods and Applications (Springer Handbooks of Computational Statistics Series), Springer, Heidelberg, Dordrecht, London, New York, NY, Vol. II, pp. 655-690.

Choi, E.P., Wong, J.Y., Lo, H.H., Wong, W., Chio, J.H. and Fong, D.Y. (2016), "The association between smartphone dating applications and college students' casual sex encounters and condom use”, Sexual and Reproductive Healthcare, Vol. 9, pp. 38-41, doi: 10.1016/j.srhc.2016.07.001.

Cohen, J. (1988), "The effect size", Statistical power analysis for the behavioral sciences, pp. 77-83.

Condie, J., Lean, G. and James, D. (2018), "Tinder matters: swiping right to unlock research fields", in Costa, C. and Condie, J. (Eds), Doing Research in and on the Digital: Research Methods across Fields of Inquiry, Routledge, London.

Cozby, P.C. (1973), "Self-disclosure: a literature review", Psychological Bulletin, Vol. 79 No. 2, p. 73.

Davari, D. and Jang, S. (2021), "Visit intention of non-visitors: a step toward advancing a people-centered image", Journal of Destination Marketing and Management, Vol. 22, 100662.

David, G. and Cambre, C. (2016), "Screened intimacies: Tinder and the swipe logic", Social Media + Society, Vol. 2 No. 2, doi:10.1177/2056305116641976.

Derlega, V.J., Metts, S., Petronio, S. and Margulis, S.T. (1993), Self-Disclosure, Sage, Newbury Park, CA.

Desjarlais, M. and Joseph, J.J. (2017), "Socially interactive and passive technologies enhance friendship quality: an investigation of the mediating roles of online and offline self-disclosure", Cyberpsychology, Behavior, and Social Networking, Vol. 20 No. 5, pp. 286-291, doi: 10.1089/cyber.2016.0363.

Dornyei, Z. (2007), Research Methods in Applied Linguistics, Oxford University Press, New York.

Duguay, S. (2017), "Dressing up Tinderella: interrogating authenticity claims on the mobile dating app Tinder", Information, Communication and Society, Vol. 20 No. 3, pp. 351-367.

Farci, M., Rossi, L., Boccia Artieri, G. and Giglietto, F. (2017), "Networked intimacy. Intimacy and friendship among Italian Facebook users", Information, Communication and Society, Vol. 20 No. 5, pp. 784-801, doi: 10.1080/1369118X.2016.1203970. 
Fornell, C. and Larcker, D.F. (1981), "Evaluating structural equation models with unobservable variables and measurement error", Journal of Marketing Research, Vol. 18 No. 1, pp. 39-50.

Gajić, T., Petrović, M.D., Blešić, I., Radovanović, M.M. and Syromiatnikova, J.A. (2021), "The power of fears in the travel decision-covid-19 against lack of money", Journal of Tourism Futures, doi: 10.1108/JTF-032021-0064.

Garton, L., Haythornthwaite, C. and Wellman, B. (1999), "Studying on-line social networks", in Jones, S. (Ed.), Doing Internet Research: Critical Issues and Methods for Examining the Net, Sage, Thousand Oaks, CA, pp. 75-105.

Gefen, D., Straub, D. and Boudreau, M.C. (2000), "Structural equation modeling and regression: guidelines for research practice", Communications of the Association for Information Systems, Vol. 4 No. 1, p. 7.

Gibbs, J.L., Ellison, N.B. and Heino, R.D. (2006), "Self-presentation in online personals: the role of anticipated future interaction, self-disclosure, and perceived success in Internet dating", Communication Research, Vol. 33 No. 2, pp. 152-177, doi: 10.1177/0093650205285368.

Greene, K., Derlega, V.J. and Mathews, A. (2006), "Self-disclosure in personal relationships", The Cambridge Handbook of Personal Relationships, pp. 409-427.

Hair, J.F., Hult, G.T.M., Ringle, C.M. and Sarstedt, M. (2014), A Primer on Partial Least Squares Structural Equation Modeling (PLS-SEM), Sage Publications, Thousand Oaks, California.

Hair, J.F., Black, W.C., Babin, B.J. and Anderson, R.E. (2018), Multivariate Data Analysis, 8th ed., Cengage Learning.

Hair, J.F., Risher, J.J., Sarstedt, M. and Ringle, C.M. (2019), "When to use and how to report the results of PLS-SEM", European Business Review, Vol. 31 No. 1, pp. 2-24, doi: 10.1108/EBR-11-2018-0203.

Horton, J. and Zeckhauser, R. (2016), "Owning, using and renting: some simple economics of the 'sharing economy'”, Working Paper No. 22029, NBER, doi: 10.3386/w22029.

Houghton, D., Joinson, A., Caldwell, N., Marder, B. and Collins, E. (2018), "Photographic disclosure in Facebook and relational closeness with others", Proceedings of the 51st Hawaii International Conference on System Sciences.

James, D., Condie, J. and Lean, G. (2019), "Travel, Tinder and gender in digitally mediated tourism encounters", The Geographies of Digital Sexuality, Palgrave Macmillan, Singapore, pp. 49-68.

Jones, S.L. and Shah, P.P. (2016), "Diagnosing the locus of trust: a temporal perspective for trustor, trustee, and dyadic influences on perceived trustworthiness", Journal of Applied Psychology, Vol. 101, pp. 392-414.

Jourard, S.M. (1971), "Self-disclosure", An Experimental Analysis of the Transparent Self.

Jourard, S.M. and Lasakow, P. (1958), "Some factors in self-disclosure", The Journal of Abnormal and Social Psychology, Vol. 56 No. 1, p. 91.

Kallis, R.B. (2020), "Understanding the motivations for using Tinder", Qualitative Research Reports in Communication, Vol. 21 No. 1, pp. 1-8, doi: 10.1080/17459435.2020.1744697.

Koohikamali, M., Peak, D.A. and Prybutok, V.R. (2017), "Beyond self-disclosure: disclosure of information about others in social network sites", Computers in Human Behavior, Vol. 69, pp. 29-42, doi: 10.1016/j.chb. 2016.12.012.

Krasnova, H., Spiekermann, S., Koroleva, K. and Hildebrand, T. (2010), "Online social networks: why we disclose", Journal of Information Technology, Vol. 25 No. 2, pp. 109-125, doi: 10.1057/jit.2010.6.

Laurenceau, J.P., Rivera, L.M., Schaffer, A.R. and Pietromonaco, P.R. (2004), "Intimacy as an interpersonal process: current status and future directions", Handbook of Closeness and Intimacy, pp. 61-78.

Lee, S.M. (2017), "Effect of food neophobia on the relationships among perceived service attributes, brand trust, satisfaction and behavioral intention of franchise snack bar", Culinary Science and Hospitality Research, Vol. 23 No. 1, pp. 58-65.

Lee, J. (2020), “'Friending' journalists on social media: effects on perceived objectivity and intention to consume news", Journalism Studies, Vol. 21 No. 15, pp. 2096-2112, doi: 10.1080/1461670X.2020. 1810102.

Leurs, E. and Hardy, A. (2019), "Tinder tourism: tourist experiences beyond the tourism industry realm", Annals of Leisure Research, Vol. 22 No. 3, pp. 323-341, doi: 10.1080/11745398.2018.1553678. 
Li, L.M.W., Chen, Q., Gao, H., Li, W.Q. and Ito, K. (2020), "Online/offline self-disclosure to offline friends and relational outcomes in a diary study: the moderating role of self-esteem and relational closeness", International Journal of Psychology, Vol. 56, doi: 10.1002/ijop.12684.

Lieberman, A. and Schroeder, J. (2020), "Two social lives: how differences between online and offline interaction influence social outcomes", Current Opinion in Psychology, Vol. 31, pp. 16-21, doi: 10.1016/j. copsyc.2019.06.022.

Lin, N. and Roberts, K.R. (2020), "Using the theory of planned behavior to predict food safety behavioral intention: a systematic review and meta-analysis", International Journal of Hospitality Management, Vol. 90, 102612, doi: 10.1016/j.jijhm.2020.102612.

Lin, R. and Utz, S. (2017), "Self-disclosure on SNS: do disclosure intimacy and narrativity influence interpersonal closeness and social attraction?", Computers in Human Behavior, Vol. 70, pp. 426-436, doi: 10.1016/j.chb.2017.01.012

Lomanowska, A.M. and Guitton, M.J. (2016), "Online intimacy and well-being in the digital age", Internet Interventions, Vol. 4, pp. 138-144, doi: 10.1016/j.invent.2016.06.005.

Ma, X., Hancock, J.T., Lim Mingjie, K. and Naaman, M. (2017), "Self-disclosure and perceived trustworthiness of Airbnb host profiles", Proceedings of the 2017 ACM Conference on Computer Supported Cooperative Work and Social Computing, pp. 2397-2409, doi: 10.1145/2998181. 2998269.

Malloch, Y.Z. and Zhang, J. (2019), "Seeing others receive support online: effects of self-disclosure and similarity on perceived similarity and health behavior intention", Journal of Health Communication, Vol. 24 No. 3, pp. 217-225, doi: 10.1080/10810730.2019.1595226.

Matiza, T. (2020), "Post-COVID-19 crisis travel behaviour: towards mitigating the effects of perceived risk", Journal of Tourism Futures, doi: 10.1108/JTF-04-2020-0063.

Mayer, R., Davis, J. and Schoorman, F. (1995), "An integrative model of organizational trust", The Academy of Management Review, Vol. 20 No. 3, pp. 709-734.

McCroskey, J.C. and Teven, J.J. (1999), "Goodwill: a reexamination of the construct and its measurement", Communications Monographs, Vol. 66 No. 1, pp. 90-103.

McKnight, D.H. and Chervany, N.L. (2001), "What trust means in e-commerce customer relationships: an interdisciplinary conceptual typology", International Journal of Electronic Commerce, Vol. 6 No. 2, pp. 35-59.

Memon, M.A., Ting, H., Cheah, J.H., Thurasamy, R., Chuah, F. and Cham, T.H. (2020), "Sample size for survey research: review and recommendations", Journal of Applied Structural Equation Modeling, Vol. 4 No. 2, pp. 1-20.

Miller, E.L. (2019), "Mind, body and boundaries: self-presentation on the Nordic LGBTQ online dating scene", Frontiers in Psychology, Vol. 10, doi: 10.3389/fpsyg.2019.02770.

Naidoo, R. (2020), "A multi-level influence model of COVID-19 themed cybercrime", European Journal of Information Systems, Vol. 29 No. 3, pp. 306-321.

Nayar, B. and Koul, S. (2020), "From likes to love: trust catalysing the digital romantic journey", Global Knowledge, Memory and Communication. doi: 10.1108/GKMC-01-2020-0002.

Nemec Zlatolas, L., Welzer, T., Hölbl, M., Heričko, M. and Kamišalić, A. (2019), "A model of perception of privacy, trust, and self-disclosure on online social networks", Entropy, Vol. 21 No. 8, p. 772, doi: 10.3390/ e21080772.

Nitzl, C., Roldan, J.L. and Cepeda, G. (2016), "Mediation analysis in partial least squares path modeling: helping researchers discuss more sophisticated models", Industrial Management and Data Systems, Vol. 116 No. 9, pp. 1849-1864.

Nora, L. (2019), "Testing customer's knowledge on customer intimacy and its impact on repurchase intention", VINE Journal of Information and Knowledge Management Systems, Vol. 49, p. 4, doi: 10.1108/ VJIKMS-03-2019-0041.

Nunnally, J.C. (1978), "An overview of psychological measurement", Clinical Diagnosis of Mental Disorders, pp. 97-146.

Ogba, K.T., Onyishi, I.E. and Chukwuorji, J.C. (2019), "Self-disclosure in intimate relationships: moderating role of online moral foundations", Current Psychology, Vol. 40, pp. 4785-4790, doi: 10.1007/s12144-01900420-9.

PAGE $14 \mid$ JOURNAL OF TOURISM FUTURES $\mid$ VOL. $\mathbf{m}$ NO. $\mathbf{m}$ 
O'Sullivan, P.B. and Carr, C.T. (2018), "Masspersonal communication: a model bridging the massinterpersonal divide", New Media and Society, Vol. 20 No. 3, pp. 1161-1180, doi: 10.1177/ 1461444816686104

Pang, H. (2018), "WeChat use is significantly correlated with college students' quality of friendships but not with perceived well-being", Heliyon, Vol. 4 No. 11, doi: 10.1016/j.heliyon.2018.e00967.

Park, N., Jin, B. and Jin, S.A.A. (2011), "Effects of self-disclosure on relational intimacy in Facebook", Computers in Human Behavior, Vol. 27 No. 5, pp. 1974-1983, doi: 10.1016/j.chb.2011.05.004.

Petrychyn, J., Parry, D.C. and Johnson, C.W. (2020), "Building community, one swipe at a time: hook-up apps and the production of intimate publics between women", Health Sociology Review, Vol. 29, pp. 249-263, doi: 10.1080/14461242.2020.1779106.

Ponder, N., Holloway, B.B. and Hansen, J.D. (2016), "The mediating effects of customers' intimacy perceptions on the trust-commitment relationship", Journal of Services Marketing, Vol. 30 No. 1, pp. 75-87, doi: 10.1108/JSM-04-2014-0117.

Prager, K.J. (1997), The Psychology of Intimacy, Guilford Press, NY.

Qian, H. and Scott, C.R. (2007), "Anonymity and self-disclosure on weblogs", Journal of Computer-Mediated Communication, Vol. 12 No. 4, pp. 1428-1451.

Ramayah, T., Cheah, J., Chuah, F., Ting, H. and Memon, M.A. (2018), Partial Least Squares Structural Equation Modeling (PLS-SEM) Using smartPLS 3.0: An Updated Guide and Practical Guide to Statistical Analysis, 2nd ed., Pearson, Kuala Lumpur.

Rau, P.L.P., Gao, Q. and Ding, Y. (2008), "Relationship between the level of intimacy and lurking in online social network services", Computers in Human Behavior, Vol. 24 No. 6, pp. 2757-2770, doi: 10.1016/j.chb. 2008.04.001.

Reis, H.T. and Shaver, P. (1988), "Intimacy as an interpersonal process", in Duck, S.W. (Ed.), Handbook of Personal Relationships, Wiley, pp. 367-389.

Rheu, M., Shin, J.Y., Peng, W. and Huh-Yoo, J. (2020), "Systematic review: trust-building factors and implications for conversational agent design", International Journal of Human-Computer Interaction, Vol. 37, pp. 81-96, doi: 10.1080/10447318.2020.1807710.

Rodrigues, C. and Rodrigues, P. (2019), "Brand love matters to Millennials: the relevance of mystery, sensuality and intimacy to neo-luxury brands", Journal of Product and Brand Management, Vol. 28 No. 7, pp. 830-848, doi: 10.1108/JPBM-04-2018-1842.

Ryff, C.D. and Singer, B. (2000), "Interpersonal flourishing: a positive health agenda for the new millennium", Personality and Social Psychology Review, Vol. 4 No. 1, pp. 30-44.

Ryu, K. and Jang, S. (2006), "Intention to experience local cuisine in a travel destination: the modified theory of reasoned action", Journal of Hospitality and Tourism Research, Vol. 30 No. 4, pp. 507-516, doi: 10.1177/ 1096348006287163.

Sperry, L. (2010), "Intimacy: definition, contexts, and models for understanding its development and diminishment", in Carlson, J. and Sperry, L. (Eds), Recovering Intimacy in Love Relationships: A Clinician's Guide, Routledge, NY.

Su, L., Lian, Q. and Huang, Y. (2020), "How do tourists' attribution of destination social responsibility motives impact trust and intention to visit? The moderating role of destination reputation", Tourism Management, Vol. 77, doi: 10.1016/j.tourman.2019.103970.

Tang, J.H. and Wang, C.C. (2012), "Self-disclosure among bloggers: re-examination of social penetration theory", Cyberpsychology, Behavior, and Social Networking, Vol. 15 No. 5, pp. 245-250.

Timmermans, E. and De Caluwé, E. (2017), "To Tinder or not to Tinder, that's the question: an individual differences perspective to Tinder use and motives", Personality and Individual Differences, Vol. 110, pp. 74-79, doi: 10.1016/j.paid.2017.01.026.

Tinder (2020), "Tinder newsroom", Tinder, 24 September, available at: https://www.tinderpressroom. com/about.

Tolstedt, B.E. and Stokes, J.P. (1983), "Relation of verbal, affective, and physical intimacy to marital satisfaction", Journal of Counseling Psychology, Vol. 30, pp. 573-580, doi: 10.1037/0022-0167.30.4.573.

Walsh, R.M., Forest, A.L. and Orehek, E. (2020), "Self-disclosure on social media: the role of perceived network responsiveness", Computers in Human Behavior, Vol. 104, 106162, doi: 10.1016/j.chb.2019.106162. 
Wang, X. and Chang, B. (2020), "The impact of the audience's continuance intention towards the vlog: focusing on intimacy, media synchronicity and authenticity", International Journal of Contents, Vol. 16 No. 2, pp. 65-77, doi: 10.5392/IJoC.2020.16.2.065.

Ward, J. (2016), "Swiping, matching, chatting: self-presentation and self-disclosure on mobile dating apps", Human IT: Journal for Information Technology Studies As a Human Science, Vol. 13 No. 2, pp. 81-95.

Ward, J. (2017), "What are you doing on Tinder? Impression management on a matchmaking mobile app", Information, Communication and Society, Vol. 20 No. 11, pp. 1644-1659, doi: 10.1080/1369118X.2016. 1252412.

Wellman, B. (1997), "An electronic group is virtually a social network", Culture of the Internet, Vol. 4, pp. 179-205.

Zhang, C., Anthony Wong, I., Zhang, X. and Fyall, A. (2020), "From online community to offline travel companions: technology-mediated trust building and ad hoc travel group decision making", Journal of Hospitality and Tourism Research, Vol. 44 No. 7, pp. 1101-1125, doi: 10.1177/1096348020934159.

\section{About the author}

Kyrie Eleison Munoz is a researcher at the National Kaohsiung University of Hospitality and Tourism, Taiwan where he also obtained his International Master's degree. His research interests include consumer behaviour, crisis response, LGBTQ and gender, and education in the context of tourism and hospitality. He is currently a student at the Institute of Service Science, National Tsing Hua University in Taiwan. Kyrie Eleison Munoz can be contacted at: kamunoz1@alum.up.edu.ph

For instructions on how to order reprints of this article, please visit our website: www.emeraldgrouppublishing.com/licensing/reprints.htm Or contact us for further details: permissions@emeraldinsight.com 